Abgar Renault, ex-Ministro da Educação e Cultura é membro da Academia Brasileira de Letras.

\title{
A Fratura exposta do sistema de ensino brasileiro
}

Temos por excessivamente rigorosas as críticas lançadas dia a dia por vários arcos de flexa ao sistema geral da educação brasileira; exibe ela, sem dúvida alguma, numerosas falhas, defeitos e fraquezas, mas neste mundo perplexo de transição os aspectos negativos multiplicam-se, avultam e causam impressão mais profunda do que em situações sociais menos carregadas de apreensões. Como a educação é, simultaneamente, efeito e causa, pois é expressão da sociedade e, ao mesmo tempo, procura ser instrumento de influências sobre ela para impor-Ihe outra forma e aperfeiçoá-la, e ainda pelo fato de que, sendo, por índole, aparelho conservador, que visa resguardar a tradição, não lhe é possível, por muito que se esforce, acompanhar o passo estugado das transformações sociais e tende a ser sempre retardia.

Nas condições de catástrofes do mundo atual, em que o senso comum se tornou o menos comum dos sensos, apesar do seu sentido inaugural no exercício da inteligência, como a sua própria denominação está a indicar, é extremamente improvável que a educação alcance o grau de eficácia por todos almejado, mesmo nos países já desenvolvidos.

Em primeiro lugar, é muito difícil atualizar-Ihe a instrumentação, pois numerosos especialistas hesitam em adotar, sem apoio em pesquisas numerosas, as modificações sugeridas por grupos que entendem dever a escola tradicional transformar-se rápida e completamente. Um exemplo: a introdução nas salas de aula do que se convencionou denominar tecnologia educacional parece imediatamente aceitável e, todavia, oferece o risco de embotar o gume da inteligência por excluir completamente, em muitos casos, o seu normal exercício. Outro exemplo: a liberdade reinante nos recintos de estudos está a ameaçar a autoridade do professor e a instalar a indisciplina onde a ordem não pode deixar de reinar. 
Não se afigura necessário por em alto relevo o crescimento demográfico, pois esse fator vem agravando visivelmente, ainda nos olhos mais distraídos, os problemas educacionais, em especial nos países em desenvolvimento, onde esse fato se associa indissoluvelmente a penúria econômica, tornando, de uma parte, precária a assistência que a escola tem de oferecer a sociedade e, de outra, criando o problema da dúvida sobre a utilidade da educação em face do mercado de trabalho e, por via de conseqüência, a mutilação ou aniquilamento das vocações individuais, que se vêem, subitamente, impossibilitadas do exercício de certas profissões ou, como ocorre em muitos países, forçadas a adotar, como se de sua escolha fosse, linha profissional que não representa o seu caminho.

Bastaria, aliás, para indicar os danos do excesso demográfico na área da educação a carência de professores, que não satisfazem em número e não atendem em qualidade o de que necessitamos.

Além disso, a complexidade e as calamidades do mundo de hoje refletem-se na escola, que aspira a recolher e espelhar, transformando-os em objeto de estudo, os problemas que afligem o homem; origina-se daí tremenda sobrecarga curricular, que ameaça com o seu peso arrastar a escola ao desabamento e é agravada pela total ausência de senso a que já nos referimos e de que é prova este fato: a proposta de inclusão no curriculum da escola de primeiro grau de um item consagrado à preparação para a morte...

Nem é possível esquecer os danos causados pelos meios de comunicação: não apoiam, nem completam a escola; desafiam-na e confundem e inutilizam o seu trabalho. Haja vista o que vem ocorrendo com a língua nacional, diariamente destroçada nas coisas mais elementares, a começar pela pronúncia de palavras de uso corrente, e, pior ainda, a doutrinação para a violência, acerca da qual declarou, há pouco, o Sr. Ministro das Comunicações: "O Brasil está pagando, a cada ano, milhões de dólares para liquidar a sua juventude; a cada 100 horas das programações vendidas ao nosso país, o espectador assiste em média 12 assassínios, 21 fuzilamentos, 20 acidentes com armas de fogo, 20 lutas, 9 facadas, 4 quedas, 9 incêndios, 2 atropelamentos, 6 batidas propositadas, 2 linchamentos, 1 explosão, 9 chantagens, 6 tentativas de suicídio, 32 ameaças veladas". Em face de tais exemplos de violência humana, é grave, mas parece muito insignificante o fato de não aparecer em nossas novelas um só livro em nenhum lugar, nem mesmo jornais e revistas: nin-
guém lê.

Como quer que seja, considerada em seu conjunto, a educação brasileira oferece a imagem, tantas vezes usada, da pirâmide invertida, sem base de sustentação, que não se sabe como se mantém de pé, já que o ensino primário - sua natural pedra angular - não corresponde nem em número nem em qualidade ao de que necessita o nosso país. Em verdade, o ensino primário é a fratura exposta do nosso sistema nacional de ensino, exposta - dizemos - em razão de ser visível e tocável e pelo motivo da sua extrema gravidade, que ameaça de paralisia todo o sistema a que pertence ou o falsifica pela sua importância fundamental, capaz, pelo seu poder de contágio, de contaminá-lo todo por inteiro. 
O de que padece, portanto, substancialmente, todo o nosso sistema educacional tem origem nas deficiências profundas do nosso ensino elementar. Como afirmou em palavras insubstituíveis, o saudoso educador paulista e nosso caro amigo Almeida Júnior, "Numa democracia sem ensino primário generalizado e eficiente, não pode haver ensino médio que valha e, sem este, o ensino superior não justificará alcançar o nome que lhe damos. "Realmente, assiste razão completa a Almeida Júnior, pois conseguimos armar gravíssimo círculo vicioso, que não logramos desarticular ainda, a despeito dos continuados esforços do Governo Federal, notadamente a partir da Revolução de 1964, expressos em associação com os governos estaduais e com os governos municipais, mediante auxílios materiais e técnicos, merecendo especial menção os fundos de participação dos Estados e dos Municípios e o salário-educação. Eis o círculo vicioso a que aludimos: não é bom, em geral, o ensino de nível superior por não ser bom o ensino de nível médio; este, igualmente, não pode ser bom porque bom não é o ensino primário, que, por sua vez, é mau por serem maus aqueles, sim - aqueles, pois o professor do primeiro nível é, hoje, preparado não só em escolas de nível médio, senão também em escolas de nível superior, que são as faculdades de educação.

Assim, apesar do muito que tem feito o Governo Federal, temos, aos poucos, perdido de vista completamente a fundamental, insubstituivel função educativa do ensino primário; porque ele não exista em todos os lugares onde deve existir ou porque exista insuficientemente ou exista e não funcione ou funcione mal, uma idade preciosamente significativa perde-se em si mesma, intelectual, moral, física, religiosa e civicamente, para não falar nos dons inapreciáveis da sensibilidade geral e da sensibilidade artística que se malbaratam ou se embotam e se perdem para sempre. Estamos esquecidos - parece - de que a criança não é um adulto em miniatura, os homúnculos dos fisiologistas do século XVIII, mas um tipo suigeneris, uma forma específica de ser.

Todavia, o ensino primário é o ensino universal, o ensino de todos, o ensino sine qua non; é o mínimo que o Estado deve ao homem. Na situação geral do mundo, em cada grupo de três adultos, um não sabe ler e escrever, nem fazer as quatro operações básicas, e o mais penoso é que, na maioria dos países, alta porcentagem dos analfabetos pertence às faixas etárias mais jovens, isto é, são ainda crianças. E o Brasil está, infelizmente, nessa categoria de países: se imaginarmos 6 milhões de crianças na primeira série da escola de primeiro grau e se as acompanharmos, verificaremos que 5 milhões chegam ao final dessa série, 2 milhões atingem a segunda e apenas 500 mil alcançam a oitava.

Que vem acontecendo? Qual a razão radical, em nosso país, desse estado de cousas na área da educação elementar? Desafortunadamente, não há uma razão só que explique tudo; as razões surgem aos bandos, e é difícil isolá-las tamanha e tão íntima a sua solidariedade.

Não obstante, tentaremos indicar aquelas que nos parecerem mais gerais, mais vigorosas, mais atuantes. 
A primeira, a mais antiga, a que mais se invoca e a que se irrogam todas as responsabilidades é a penúria de recursos, que tanto mais pesa quanto maior a porcentagem da população que deva ser atendida. São rasos os cofres públicos, ralas as quantias que contêm para custear o ensino de todos, muitas as exigências do próprio ensino a clamar por socorro. Dentre essas a mais eloqüente é, sem dúvida, a fraca remuneração atribuída às eminentes funcões do professor primário. Aqui está, seguramente, a capital razão de tudo. A solução é dura de achar, mas tem de ser achada, se quizermos, não somente sobreviver como sociedade organizada, senão também vencer o estágio social em que estamos atolados. Aqui, mais do que em qualquer outro sector, cabe conseguir quotas de sacrifício de outros serviços para ajuntar recursos, providência tanto mais de tomar quanto se atente em que a educação é processo associativo que beneficia a todos que a ela juntarem seus esforços. Como imaginar, por exemplo, a educação sanitária fora da escola e, pois, por que a ela não associar os recursos dos serviços de saúde pública?

De igual importância é, sem qualquer dúvida, a adoção de uma linha da mais rigorosa economia em todos os gastos públicos, entregando à educação tudo quanto iria ser gasto e, em boa hora, deixou de ser. O Brasil tem a vocação do vistoso, do excessivo, do suntuário, do anti-econômico; é país pobre que gasta a sua pobreza em muitas cousas vãs. Infelizmente, são inumeráveis os casos em que a administração pública despende cinco onde e quando podia e devia gastar apenas um. Para não sair da área da educação: quantos grupos escolares, quantas escolas isoladas existem no Brasil que prestariam o mesmo serviço se houvessem custado um terço do que custaram? Que importâncias gastas com o ensino superior notadamente com uma incompreensível gratuidade indiscriminada, poderiam ser aplicadas no ensino primário? O que se gasta em nosso país em papel timbrado em relevo, em luzes espetaculosas, em edifícios durante horas em que não funcionam, em luxos e louçarias de toda espécie é cousa de espantar. As despesas com telefonemas particulares em repartições públicas, o uso do correio, do telégrafo e de veículos públicos para fins pessoais devem alcançar níveis elevados. A descentralização, que parecia capaz de coibir os excessos não visíveis no regime de centralização rígida, veio a revelar-se incapaz, porque à descentralização não corresponde responsabilidade. É esse o caso de numerosas autarquias, empresas públicas, sociedades de economia mista e fundações de direito público.

A nossa experiência administrativa, que não é pequena, pôs ao vivo aos nossos olhos quanto dinheiro público se gasta mal ou indevida e ilegalmente, que pode ser poupado com um pouco de diligência. Estamos cientes de que, nos dias de hoje, educação é guerra e não há guerras baratas; sem dúvida não há como evitar que ela seja cara, mas há, seguramente, como impedí-la de ser mais cara do que deve e do que podemos pagar por ela.

Eis ai cousas triviais, mas o Brasil precisa de muitas cousas triviais - como, por exemplo, ensino primário.

Não valerá formar bem o professor para pagar-the mal. Por isso 
foi que em nossa enumeração figura em primeiro lugar esse aspecto econômico do problema.

Ninguém ignora que a origem da dificuldade está na própria natureza do ensino primário, no fato de ser ele o ensino para todos; isso, porém, não nos exime do dever de utilizar todos os meios administrativos para alcançar a solução salvadora, os quais podem ser diretos e indiretos, isto é, podem existir dentro da própria área da educação e, pois, nas suas leis de meios ou fora dela, como nos exemplos, que há pouco citamos, da utilização de meios oriundos da economia feita em quaisquer orçamentos ou dos saldos nelas existentes por qualquer motivo. Sabemos que existirão sempre óbices muitos numerosos a esse tipo de procedimento administrativo, pois a execução orçamentária está sujeita a regras rígidas e a certos princípios judiciosos como o de que não há estorno de verhas. Nada disso deve importar. Trata-se de caso de salvação nacional em face do qual tudo deve ceder.

Dentro da própria área da educação há também muitos processos indiretos de obter meios para melhorar a remuneração dos professores e melhor empregar os dinheiros públicos na criação e localização de unidades escolares de qualquer tipo, evitando o arbítrio de que resulta sempre desperdício. Já que não é possível dar ensino primário ao mesmo tempo a todas as crianças em idade escolar, que se cuide de oferecê-lo onde a escola seja mais bem aproveitada, isto é, possa ter a maior matrícula possível, onde, portanto, maior rendimento dê.

O melhor aproveitamento dos prédios significa a possibilidade de aumentar a matrícula cerca de $20 \%$ sem necessidade de aumento de salas, bastando que estas sejam em número de 5 ou o múltiplo de 5 e que, em vez de dar-se o sueto semanal num só dia a todo o conjunto da escola, se dê a cada turma num dia, por forma que fique sempre vaga uma sala, a qual será ocupada por novas turmas durante toda a semana escolar, que é de 5 dias.

Outro ponto em que deve ser feita economia está na abolição do expediente exatamente contrário, que consiste em amontoar crianças em turnos superpostos, comprimindo os horários de tal forma, que um curso de quatro anos se reduz a dois e meio no máximo.

Igualmente, cumpre evitar o absurdo de nomeação de professoras além do número estritamente necessário para a matrícula em cada ano letivo. É comum que imperativos políticos imponham à administração esse ônus terrivei de manter sempre em cada escola número de docentes mais alevado do que o por ela exigido, com indefensável sobrecarga para os cofres públicos. Também isso é trivial, realmente é, mas não se pratica, pois é hábito brasileiro reconhecer a existência do mal, diagnosticá-lo, localizá-lo e deixá-lo à vontade onde está e como está...

Nem por ser a remuneração do professorado o ponto mais sensível das condições gerais do ensino primário nacional será possível deixar sem exame a sua preparação, como se opera, onde se faz, o que falha e como corrigir. 
Sabe-se que apenas $57 \%$ dos professores da primeira à 4 ? série são habilitados para a sua delicadíssima função, ao passo que nas escolas rurais essa porcentagem baixa para cerca de $20 \%$. Dos 9.214 candidatos que compareceram às provas do último concurso para ingresso no magistério do Estado de São Paulo apenas 67 foram aprovados. É como se o Brasil estivesse forçando uma empreitada inédita no mundo - ensinar a ler por meio de analfabetos.

A outra amarga conclusão que se infere dos últimos números é que os estabelecimentos ora prepostos à formação de profesłsores para escolas de $1^{\circ}$ grau não são capazes de cumprir a sua missão. 0 segredo das antigas escolas normais, que eram insuficientes, mas, pelo geral, levavam a cabo o seu dever, estava na eficácia dos meios, ainda que modestos, e na firme segurança dos objetivos em mira, a que se aliava uma atmosfera saturada do sentido de unidade ou, melhor, de unicidade de propósitos, a qual não se multipartia, nem se modificava, atraída por metas laterais, a unicidade espiritual, magisterial, profissional, com uma só direção. E por falar em escolas normais: que é feito das classes anexas onde os estudantes ensinavam experimentalmente ler, escrever e contar?

Ao desaparecimento dessa atmosfera veio juntar-se a formação dos mestres em estabelecimentos de ensino de nível superior, a qual oferece a ilusão de um status intelectual e social que não quer coordenar-se com a tarefa liminar, aparentemente tão humilde, da escola primária, mas condição sem a qual nada existe em nenhuma área da educação.

Agrava-se tal situação por força de distinguir-se incorretamente professor primário de professor de ensino médio ou, como se dizia outrora, professor secundário. A preparação para o magistério até a 4 . ou 6 . série do primeiro grau é feita em curso de $2^{\circ}$. grau e para o mesmo magistério ou para o de especialidade pedagógica em toda a escola de 1. grau ou nesta e também da de 2. grau é feita em nivel superior. Isso é pedagogicamente lógico, mas estará dando resultados, ainda que essa preparação seja realmente proveitosa? Como na realidade se comporta o professor cuja preparação está prevista na segunda hipótese, isto é, em nível superior? Ecomo esperar candidatos em número suficiente no primeiro caso, se poderão, com pouco mais, alcançar o magistério de $2^{\circ}$ grau mais importante socialmente e menos mal remunerado? E será que a livre circulação entre a escola de $1^{\circ}$ grau e a de $2^{\circ}$ irá fixar o professor na 1 ? ? Onde ficará ele afinal? A que ensino se dedicará, ao cabo de contas?

Dissolveram-se a intimidade profunda e a solidariedade radical entre a escola de preparação de mestres primários e a sua finalidade, não capital apenas, mas única, de construir os elementos imprescindíveis aos demais conhecimentos humanos, por mais altos que sejam; e dissolveram-se sob a pressão do processo de formação, que não realiza o que lhe cabe, isto é, preparar o professor das séries iniciais do 1. grau, cuja insubstituível tarefa consiste em ensinar a ler, escrever e contar associada, naturalmente, à função básica de educar num momento crucial da vida da criança. Quem alfabetizará as novas geracões? - Eis a pergunta angustiada que formulam todos os que se interessam pelo futuro deste país. 
Do ponto de vista administrativo, parece-nos que se impõe a experiência da municipalização do ensino do $1^{\circ}$ grau, com a assistência técnica e financeira dos Estados e da União, na qual se inclui irrecusavelmente a obtenção de recursos, antes de mais nada, e sobretudo, para por termo à ridiculez da remuneração do professorado. Essa é a medida urgentíssima que deve ser tomada como em face de grave mal epidêmico ou, mais apropriadamente, já endêmico, juntamente com a melhoria dos processos de formação.

Neste momento, o Brasil ocupa o 57\%. Iugar no mundo e o $8^{\circ}$ na América Latina entre os países que mais gastam em educação, ao passo que o Canadá, por exemplo, além de gastar mais do que toda a América Latina, exibe o índice per capita mais elevado do mundo - 474 dólares, acompanhado de perto pela Suécia - 468 dólares.

Em 1968 - e não se alterou a situação - os países desenvolvidos gastavam 120 milhões de dólares em educação primária e os subdesenvolvidos menos de 12 milhões, ou seja, com quase um terco apenas dos habitantes destes, aqueles gastavam 10 vezes mais. Metade das matrículas escolares está nos primeiros, embora as crianças em idade escolar seja a 6 ? parte do grupo etário correspondente em escala mundial. Os países subdesenvolvidos, que são duas vezes mais povoados e tem três vezes mais crianças e jovens, contam apenas metade da população escolar do mundo. Não é preciso, mas é conveniente, que completemos tal quadro com estes números: aos $2 / 3$ da população mundial concentrada nos países subdesenvolvidos correspondem apenas $2 \%$ dos investimentos totais em tecnologia, o que explica o atraso e a pobreza dos países daquela categoria econômica. O desenvolvimento exige vultosa manobra, que não pode compor-se de analfabetos, e estas desaparecem somente por dois meios: a ação de mestres competentes em quantidade bastante ou a morte - caso em que são logo substituídos por novo contingente.

É necessário que o Brasil se convença de que o berço da prosperidade geral - o chamado desenvolvimento - esta na educação elementar, à qual devem ser dados imediatamente pelos Municípios, pelos Estados e pelo Governo Federal os recursos máximos, recalcando-se a segundo, terceiro e quarto planos tudo quanto não seja rigorosamente essencial. Basta de borlas, bordados, babadose badulaques. Corrijamos a formação do professor de 1. grau, que é multifária, pedante e ineficaz e na qual somente se vem cuidando dos tegumentos, largando-se ao deus-dará o cerne e a essência.

Precisamos de grave bom senso, nua simplicidade, extrema economia. 


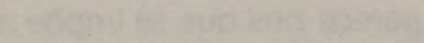

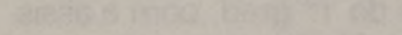

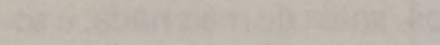

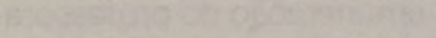

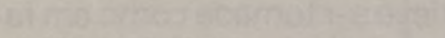

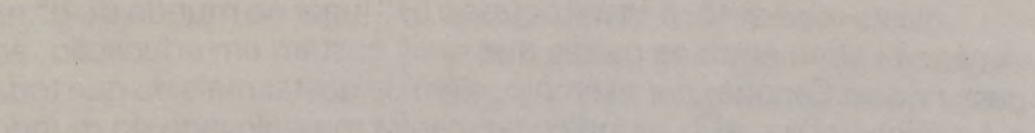

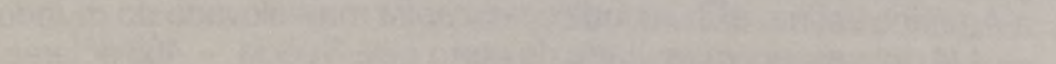

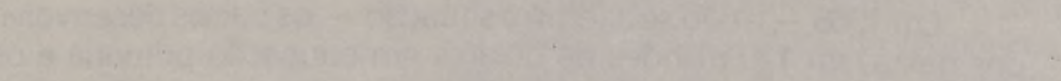

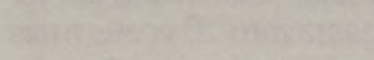

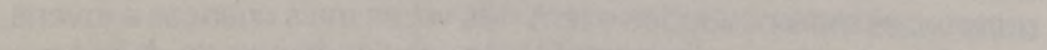

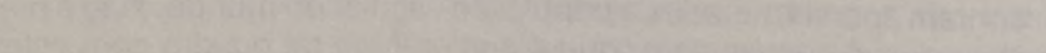

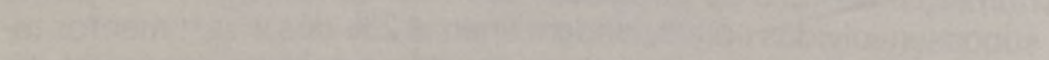

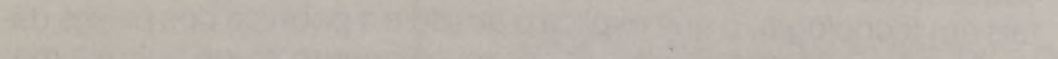

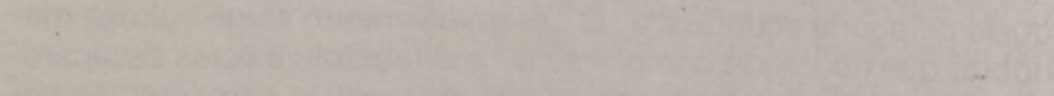
(16)

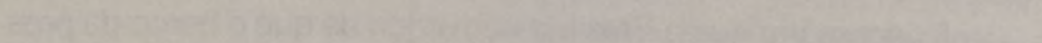
and

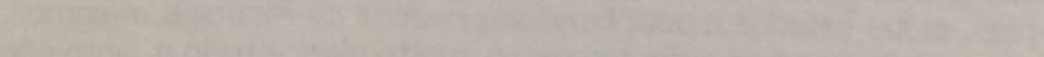

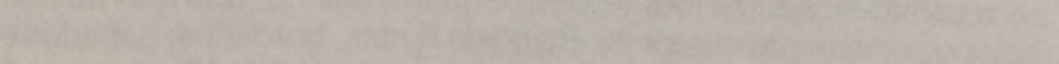

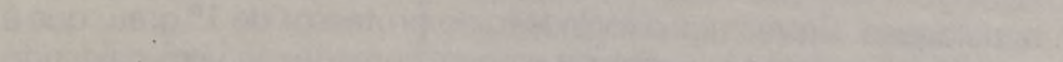

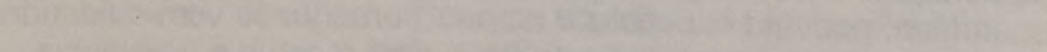

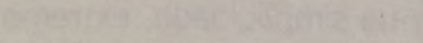

